\title{
Effects of educational versus peer discussion interventions on perceived competence in adolescents with medulloblastoma
}

\author{
Lingyun Zhu*, Haoling Gong and Yan Gao \\ Department of Neurosurgery, Jiangsu University Affiliated People's Hospital of Jiangsu University, Zhenjiang, P.R.CHINA - 212002
}

\begin{abstract}
Context: Limited documentation exists on the effectiveness of education-based (EG) versus peer discussionbased (PDG) group interventions on perceived competence of adolescents suffering from medulloblastoma. Aims: This study was conducted to investigate which of these approaches offers the more beneficial outcomes to participants. Settings and Design: In a hospital in Zhenjiang, China, a total of 45 pediatric patients with standard risk or high risk medulloblastoma were randomly assigned to the EG or PDG interventions. Methods and Material: The Self-Perception Profile for Children (SPPC) and the Life Orientation Test-Revised (LOT-R) questionnaires were used to measure perceived competence and dispositional optimism or pessimism. Statistical analysis used: Adjustment was measured before the intervention, immediately after the intervention, at two weeks after, and six months after the intervention. Results: Participants in both groups showed improvement over time. The EG participants scored themselves higher on subscales including social acceptance, global self-worth and behavioral conduct at 2 weeks compared with those in the PDG $(P<0.05)$. However, no significant differences were found between the groups at 6 months. Moreover, pessimists did not benefit more by attending an EG intervention than they did by attending a PDG intervention. Conclusion: The results show EG intervention seeming to enhance shortterm, rather than long-term, perceived competence. Longitudinal studies are warranted to further identify targeted interventions to maximize healthy survivorship.
\end{abstract}

Key words: Adolescents, Education intervention, Medulloblastoma, Peer discussion intervention, Perceived competence.

\section{INTRODUCTION}

Medulloblastoma is a type of malignant tumor that arises principally in the area of the cerebellar vermis within the posterior fossa of the cranium. Medulloblastoma accounts for $10-20 \%$ of all central nervous system (CNS) tumors in children, with peak incidence at 5 years of age. Two male occur for every female case. ${ }^{1}$ Patients with medulloblastoma are classified into "standard" and "high" risk categories based on age at diagnosis, degree of surgical resection, and disease spread. In children older than 3 years of age, long-term survival can be achieved in almost $85 \%$ of standard risk patients and $70 \%$ of high risk patients. Over the past 10 years, treatment for medulloblastoma has experienced extensive modification. Cur- rent protocols consist of maximal surgical resection, risk-based neuraxis radiation therapy, and adjuvant chemotherapy.

However, the quality of life in long-term survivors is still a major issue. ${ }^{2}$ An overwhelming majority of medulloblastoma survivors continue to suffer academic failure, psychological sequelae and unpleasant external appearance, all of which influence perceived competence. Children with cancer, such as leukemia scored themselves more negatively on perceived competence. ${ }^{3}$ Psychosocial research in recent decades has advanced our understanding of the psychosocial issues in pediatric cancer. In keeping pace with the medical achievement, psycho-
Submission Date : 28-11-2014 Revision Date : :19-01-2015 Accepted Date : :05-02-2015

DOI: $10.5530 /$ ijper.49.3.3 Correspondence Address Dr. Lingyun Zhu Department of Neurosurgery, People's Hospital of Jiangsu University

No.8Dianli Road, Runzhou District, Zhenjiang, Jiangsu Province, P.R.

CHINA-212002

Email:zhulingy2013@163. com

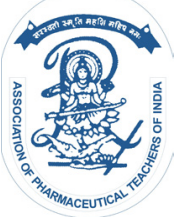

www.ijper.org 
social research has moved from helping children and parents deal with issues related to death to focus on health interventions for cancer survivors. Evidence exists that psychotherapeutic group interventions directed by therapists help the adjustment of cancer patients. ${ }^{4}$

Helgeson and cohen published a review of group support interventions for people with cancer and concluded that there were clear and consistent benefits of educationbased group interventions. ${ }^{5}$ In a recent study, the psychoeducational intervention administered was acceptable for children with cancer and the intervention group reported significantly lower scores in pain. ${ }^{6}$

Moreover, the educational intervention can enhance capacity for self-expression, emotional stability, insight and selfreflection and expand knowledge on rehabilitation in cancer patients. ${ }^{78}$ Through clinical education intervention, nurses can help adolescents maintain and improve their quality of life. ${ }^{9}$ Peer discussion intervention offers patients emotional support, improving self-confidence and promoting helpful downward comparisons (feeling lucky in comparison with others who are worse off). ${ }^{10}$

Although the benefits of the education intervention can be maintained over a 3-year period on the quality of life of women with early stage breast cancer, yielding more reliable, constructive outcomes than peer discussion group interventions, ${ }^{11}$ their influence on outcomes in pediatric medulloblastoma patients has not yet been documented.

A feeling of optimism has been shown to be positively associated with well-being. ${ }^{12}$ Previous research suggests that optimism might buffer stress and protect against distress. Gustavsson-Lilius et al. reported that optimism has beneficial effects on mental and physical health. ${ }^{13}$ It is also a predictor of good adjustment to a variety of somatic illnesses, including cancers. ${ }^{15}$

Positive self-regard serves as a coping mechanism for pediatric burn survivors. By contrast, pessimism has a negative impact the self-esteem of young adults. ${ }^{14}$ Whether or not EG intervention can help to strengthen pessimistic adolescents still remains uncertain. Our study aimed to explore whether or not educational interventions yielded better long-term effects than peer discussion group interventions in adolescents suffering from medulloblastoma.

The major measures examined here were perceived competence, including six subscales. We worked on the assumption that educational intervention would be more helpful for pessimistic adolescents than with optimistic adolescents.

\section{MATERIAL AND METHODS}

\section{Design and sample}

The local institutional review boards provided medical ethical approval. Childhood medulloblastoma survivors having medical follow-up procedures at the Department of Neurosurgery at the First People's Hospital of Zhenjiang and who met the inclusion criteria were invited to participate in the study if they were: (a) between 9 and 18 years of age, and (b) able to speak and read Chinese. Children with serious cognitive and psychological disability are excluded from the study. It is understandable that younger children may be more vulnerable to the sequelae of cancer treatment, but those younger than 9 years may have limited verbal and cognitive capacities for self-expression and be perplexed by the questionnaires. For this reason, only children aged 9 to 18 years were invited to participate in the study. Children were given verbal and written information prior to joining the study. They were invited to withdraw if they no longer wanted to participate after receiving the introduction to the day and after each activity.

\section{Nurse participants}

The nurses, all female, had a mean of 11 years of experience in central nervous system (CNS) oncology. Because the communicative behavior of nurses differs with age and gender, ${ }^{15,16}$ quota sampling was used to obtain a representative sample of nurses. Prior to the implementation of nursing consultations (approximately 9 months earlier), the nurses undertook a brief training seminar, provided by a clinical psychologist and a researcher. The seminar covered two topics: (1) patient assessment following a biopsychosocial model and (2) effective patient-centered consultation using exploratory communication skills.

\section{Procedures}

Groups were held weekly for 8 consecutive weeks. The peer discussion and education groups lasted for 60 and 45 minutes respectively. Assessments were carried out at four time points: at baseline (T0, before intervention) and when intervention finished (T1). The T2 and T3 data, collected via mailed questionnaires, each took place 2 weeks and 6 months, respectively, after the intervention.

\section{Peer discussion}

Two oncology nurses who had been previously trained attended all meetings. The peer discussion groups were facilitated by two nurses and followed semi-structured discussion. The aims were to counter feelings of alienation and isolation, to offer support and information within the group, to elucidate misperceptions and to avoid emotional distress. At the first session, after introductions 
and delivery of general information, the adolescents were encouraged to share their experiences and feelings (positive and negative), but were guided to avoid deterioration into sessions of complaint. ${ }^{17}$ Topics frequently discussed during the sessions were body image, hair loss, adjuvant therapy, nausea, and fear of recurrence. With patients' consent, a list of group members' names and addresses was shared. The discussion concluded with participants being asked to present as newspaper headlines what they felt were the most significant aspects of their experience. The research team grouped the newspaper headlines according to similar clusters and the thematic analysis was undertaken. It should be confirmed that clusters reflected their experiences and titled the clusters.

\section{Education intervention}

The educational intervention aimed to provide expert information and to develop the adolescents' control over the illness experience. The intervention was conducted in a classroom atmosphere. Information was given in lecture format. Following topics were covered in the 8 sessions: an overview of medulloblastoma (presented by the nurses), adverse effects of chemotherapy (nurse), nutrition (dietitian), exercise (physical therapist), coping strategies (clinical psychologist), communication (nurse), future health care issues (physician), and body image (image consultant).

\section{Measures}

Perceived Competence-Children's perceived competence was assessed using the revised version of SPPC. ${ }^{18}$ The SPPC assesses children's global and domain-specific perceptions of self-esteem. Subscales included in this study were Global Self-Worth, as well as five specific domains, namely scholastic competence, social acceptance, athletic competence, physical appearance, and behavioral conduct. ${ }^{19}$ The reliability of this scale has

\begin{tabular}{|c|c|c|}
\hline \multicolumn{3}{|c|}{ Table 1: Participant's characteristics } \\
\hline & PDG (n=22) & EG (n=23) \\
\hline Age, mean (SD), years & $12.2(2.7)$ & $12.9(2.8)$ \\
\hline Male/Female & $14 / 8$ & $16 / 7$ \\
\hline LOT-R, mean (SD) & $16.4(3.8)$ & $16.3(4.0)$ \\
\hline Education > 5 years, \% & 31.3 & 32.5 \\
\hline Age at diagnosis, mean, \\
years & 6.4 & 7.0 \\
\hline Stratification & & \\
\hline standard risk, M0 & 34.3 & 36.7 \\
\hline high risk, M1-M4 & 65.7 & 63.3 \\
\hline Surgery, \% & 35.4 & 38.1 \\
\hline Systemic treatment, \% & & \\
\hline Radiotherapy & 80.2 & 77.7 \\
\hline Chemotherapy & 52.4 & 50.3 \\
\hline
\end{tabular}

been confirmed in Hong Kong, China. ${ }^{20}$ The SPPC has a 4-point response format and six items on each subscale with adequate internal consistency and convergent validity. Total scores on each subscale were computed by summation of responses to items on that subscale.

The Life Orientation Test-Revised (LOT-R) is a revision of the original Life Orientation Test, ${ }^{21,22}$ developed to assess individual differences in optimism and pessimism. The reliability of this scale has been confirmed in China. ${ }^{21}$ The instrument contains 10 items. Each item is rated on a 5-point Likert scales ranging from strongly agree to strongly disagree. The items such as, "In uncertain times I usually expect the best" belong to the optimism subscale, while the items "If something can go wrong for me, it will" or "I rarely count on good things happening to me" belong to a pessimism subscale. Total LOT-R scores below the median score of 18 are used to define pessimists, whereas LOT-R scores of 18 or higher characterize optimists.

\section{Data Analysis}

The characteristics of the EG and PDG samples were compared at baseline, to guarantee the comparability of groups. $t$ tests were applied to compare the means of continuous variables for the two groups. $\chi^{2}$ analysis was used when outcome variables were categorical. Relationships between continuous variables were examined using correlation coefficients. Changes over time from T0 to T3 were compared using general linear models. We evaluated the effect size of the results using partial $\eta^{2}$ scores. Since most patients had received adjuvant therapy at the follow-up assessments, adjuvant therapy variables were used as covariates. The $a$ values were adjusted for the final results, when multiple comparisons were carried out. All data analyses were performed using SPSS software (version 14.0).

\section{RESULTS}

\section{Sample characteristics}

Among the 55 patients who were asked to participate, ten patients had relapsed and were undergoing intensive treatment, and then failed to complete the assessment. 45 patients were randomly assigned to $E G(n=22)$ or PDG ( $\mathrm{n}=23)$ interventions. Most participants $(96 \%)$ completed the questionnaires at both assessments points. Less than $15 \%$ of data was missing on any instrument subscale. There were no significant differences in demographics or medical variables between participants in the two groups (Table 1).

\section{SPCC for perceived competence}

At baseline, no significant differences were shown between the total scores of PDG and EG participants 


\begin{tabular}{|c|c|c|c|c|c|c|c|c|c|c|}
\hline \multirow{3}{*}{ Outcome } & \multicolumn{4}{|c|}{ Time } & \multirow[b]{3}{*}{$F$} & \multicolumn{5}{|c|}{ Effect } \\
\hline & TO & T1 & T2 & T3 & & \multirow{2}{*}{$\begin{array}{c}\text { Group } \\
P \\
\end{array}$} & \multirow{2}{*}{$\begin{array}{c}\text { Group } \times \text { Time } \\
\eta^{2}\end{array}$} & \multirow[b]{2}{*}{$F$} & \multirow[b]{2}{*}{$P$} & \multirow[b]{2}{*}{$\eta^{2}$} \\
\hline & \multicolumn{4}{|c|}{ Mean (SD) } & & & & & & \\
\hline $\begin{array}{l}\text { Global Self- } \\
\text { Worth }^{\mathrm{a}}\end{array}$ & & & & & 1.7 & 0.04 & 0.066 & 5.9 & 0.01 & 0.078 \\
\hline EG & $10.2(1.8)$ & $13.8(2.3)$ & $15.7(3.5)$ & $13.2(3.3)$ & - & - & - & - & - & - \\
\hline PDG & $10.4(1.6)$ & $11.9(1.9)$ & $12.7(2.6)$ & $11.8(2.4)$ & - & - & - & - & - & - \\
\hline $\begin{array}{c}\text { Scholastic } \\
\text { competence }\end{array}$ & & & & & 0.42 & 0.16 & 0.004 & 0.87 & 0.08 & 0.009 \\
\hline EG & $16.4(3.2)$ & $18.3(4.0)$ & $19.6(4.5)$ & $18.7(5.1)$ & - & - & - & - & - & - \\
\hline PDG & $16.2(5.7)$ & $18.1(3.4)$ & $19.2(4.5)$ & $18.2(3.9)$ & - & - & - & - & - & - \\
\hline $\begin{array}{c}\text { Social } \\
\text { acceptance }^{a}\end{array}$ & & & & & 1.6 & 0.04 & 0.061 & 3.4 & 0.02 & 0.068 \\
\hline EG & $8.3(2.3)$ & $10.5(2.0)$ & $12.6(1.9)$ & $10.4(3.1)$ & - & - & - & - & - & - \\
\hline PDG & $8.5(2.3)$ & $9.6(2.5)$ & $10.7(2.6)$ & $9.7(2.2)$ & -- & & - & - & - & - \\
\hline $\begin{array}{c}\text { Athletic } \\
\text { competence }\end{array}$ & & & & & 0.55 & 0.12 & 0.003 & 0.81 & 0.09 & 0.007 \\
\hline EG & $9.7(2.4)$ & $10.4(2.5)$ & $11.8(3.4)$ & $10.2(3.1)$ & - & - & - & - & - & - \\
\hline PDG & $9.4(1.0)$ & $10.7(2.3)$ & $11.6(2.3)$ & $9.9(2.3)$ & - & - & - & - & & - \\
\hline $\begin{array}{c}\text { Physical } \\
\text { appearance }^{\mathrm{a}}\end{array}$ & & & & & 3.5 & 0.03 & 0.028 & 6.3 & 0.01 & 0.035 \\
\hline EG & $8.5(1.9)$ & $9.3(1.6)$ & $10.2(3.5)$ & $9.4(3.5)$ & - & -- & - & - & - & - \\
\hline PDG & $8.1(2.2)$ & $10.7(2.5)$ & $12.6(2.6)$ & $10.8(2.6)$ & - & - & - & - & - & - \\
\hline $\begin{array}{l}\text { Behavioral } \\
\text { conduct }^{\mathrm{a}}\end{array}$ & & & & & 0.45 & 0.11 & 0.054 & 1.9 & 0.04 & 0.061 \\
\hline EG & $10.8(3.1)$ & $13.4(3.3)$ & $15.2(3.5)$ & $13.5(4.2)$ & - & - & - & - & - & - \\
\hline PDG & $11.2(3.7)$ & $12.5(3.4)$ & $13.2(2.8)$ & $12.7(2.7)$ & - & - & - & - & - & - \\
\hline
\end{tabular}

Abbreviations: $\mathrm{EG}$, education group; PDG, peer discussion group ${ }^{\mathrm{a}}$ Higher score indicates better judgment.

according to Harter's SPPC. At both T1 and T2 assessments, children in PDG scored lower on the total score as compared to subjects in EG. On the subscales, EG participants scored themselves significantly lower on physical appearance $(\mathrm{F}=3.5, P=0.03)$ and considerably higher on global self-worth and social acceptance $(\mathrm{F}=1.6$, $P=0.04)$ than did children in PDG. After controlling for a time effect, the substantial group-by-time interaction suggested that the educational intervention had a positive effect on social acceptance, global self-esteem and behavioral conduct (Table 2). Repeating the analyses with adjuvant therapy variables (radiotherapy and/or chemotherapy) and LOT-R scores as covariates generated similar results. Chemotherapy was an important factor for athletic competence $(P=0.05)$, and LOT-R score was a significant factor for physical appearance, global self-esteem and behavioral conduct $(P<0.05)$.

\section{LOT-R for perceived competence}

Comparisons of the mean scores of the children in the two groups, of both the pessimists and the optimists, on the perceived competence subscale are shown in Table 3. At T2 assessments, the scores of optimists in the EG were considerably higher on global self-esteem than those of optimists in the PDG $(P=0.04)$. Pessimists from the EG scored higher on behavioral conduct than did pessimists in the PDG $(P=0.04)$. Nevertheless, at T3 assessments, no significant differences between the two intervention groups were found.

\section{DISCUSSION}

Adolescents in both groups displayed progress in perceived competence over time. Participants in the EG scored themselves higher at T1 and T2 after interventions compared with the patients in the PDG, but not at T3, signifying that the EG intervention exhibited short-term, rather than long-term, effects. Long-term neurologic, endocrinologic, and neurocognitive sequelae are well documented in medulloblastoma survivors. All these sequelae might contribute to the short-term effect of EG intervention.

A diagnosis of medulloblastoma during adolescence adds a significant stressor to this unique period of development. A diagnosis of cancer during adolescence has the 


\begin{tabular}{|c|c|c|c|c|c|}
\hline & & \multicolumn{2}{|c|}{ Optimists } & \multicolumn{2}{|c|}{ Pessimists } \\
\hline & & EG $(n=10)$ & PDG $(n=10)$ & EG $(n=13)$ & PDG $(n=12)$ \\
\hline \multirow{6}{*}{ T0 } & Global Self-Worth & 11.4 & 11.5 & 9.3 & 9.5 \\
\hline & $\begin{array}{l}\text { Scholastic } \\
\text { competence }\end{array}$ & 17.4 & 17.1 & 15.6 & 15.5 \\
\hline & Social acceptance & 8.6 & 8.6 & 8.1 & 8.4 \\
\hline & $\begin{array}{l}\text { Athletic } \\
\text { competence }\end{array}$ & 10.8 & 10.5 & 8.9 & 8.5 \\
\hline & $\begin{array}{l}\text { Physical } \\
\text { appearance }\end{array}$ & 9.6 & 9.4 & 7.7 & 7.0 \\
\hline & $\begin{array}{l}\text { Behavioral } \\
\text { conduct }\end{array}$ & 11.5 & 11.6 & 10.3 & 10.9 \\
\hline \multirow{6}{*}{ T1 } & Global Self-Worth & 15.3 & 13.3 & 12.6 & 10.7 \\
\hline & $\begin{array}{l}\text { Scholastic } \\
\text { competence }\end{array}$ & 19 & 18.7 & 17.8 & 17.6 \\
\hline & Social acceptance & 10.9 & 10.0 & 10.2 & 9.3 \\
\hline & $\begin{array}{l}\text { Athletic } \\
\text { competence }\end{array}$ & 10.9 & 11 & 10.0 & 10.5 \\
\hline & $\begin{array}{l}\text { Physical } \\
\text { appearance }\end{array}$ & 10.2 & 12.5 & 8.6 & 9.2 \\
\hline & $\begin{array}{l}\text { Behavioral } \\
\text { conduct }\end{array}$ & 14.7 & 13.8 & 12.4 & 11.4 \\
\hline \multirow{6}{*}{ T2 } & Global Self-Worth & 18.3 & $13.8 \mathrm{a}$ & 13.7 & 11.8 \\
\hline & $\begin{array}{l}\text { Scholastic } \\
\text { competence }\end{array}$ & 19.9 & 19.8 & 19.4 & 18.7 \\
\hline & Social acceptance & 13.2 & 12.1 & 12.1 & 9.5 \\
\hline & $\begin{array}{l}\text { Athletic } \\
\text { competence }\end{array}$ & 12.4 & 12.1 & 11.3 & 11.2 \\
\hline & $\begin{array}{l}\text { Physical } \\
\text { appearance }\end{array}$ & 11.3 & 13.5 & 9.4 & 11.9 \\
\hline & $\begin{array}{l}\text { Behavioral } \\
\text { conduct }\end{array}$ & 16.1 & 15 & 14.5 & $11.7 \mathrm{a}$ \\
\hline \multirow{6}{*}{ T3 } & Global Self-Worth & 14.3 & 13.4 & 12.4 & 10.5 \\
\hline & $\begin{array}{l}\text { Scholastic } \\
\text { competence }\end{array}$ & 19.1 & 18.8 & 18.4 & 17.7 \\
\hline & Social acceptance & 11.7 & 10.8 & 9.4 & 8.8 \\
\hline & $\begin{array}{l}\text { Athletic } \\
\text { competence }\end{array}$ & 10.9 & 10.4 & 9.7 & 9.5 \\
\hline & $\begin{array}{l}\text { Physical } \\
\text { appearance }\end{array}$ & 9.8 & 10.9 & 9.1 & 10.7 \\
\hline & $\begin{array}{l}\text { Behavioral } \\
\text { conduct }\end{array}$ & 14.4 & 13.7 & 12.8 & 11.9 \\
\hline
\end{tabular}

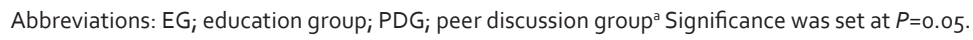

potential to challenge the development of strong peer relationships, a positive body image and future plans. ${ }^{23}$ Confidence may be difficult to attain as major decisions regarding health and well being tend to be made by others. ${ }^{24}$ Consistent with Helgeson's report, educational intervention improved psychological functioning mainly by augmenting self-perceptions, and implanting a positive body image. ${ }^{10}$ Obtaining information about one's illness and possible ways to handle it may make adolescents feel better about themselves in general and about their bod- ies. The information may have directly influenced health behaviors, which in turn enhanced self-perceptions. Interestingly, children with cancer had a more negative judgment of themselves in all the other subscales at baseline (T0), except in scholastic performance, because this is a relatively more objective construct than the other subscales. ${ }^{25}$ Other studies found social skills training and cognitive behavioral methods can improve psychosocial adjustment and coping in these situations. ${ }^{26}$ 
Curiously, in our research, peer discussion exhibited a more potent effect on physical appearance than educational intervention did. These findings are meaningful since this domain is vulnerable in children. Likewise, adolescents with cancer tend to think they are socially undesirable or a burden to parents and siblings. ${ }^{27}$ Downward comparisons (i.e. feel lucky when compared with others) can be accounted for by the positive effect of peer discussion on physical appearance. However, downward comparisons are not always positive. Children may compare other aspects of their experience, such as varying side effects of chemotherapy or number of cancerous lymph nodes. The following themes which the children were most concerned about emerged during the semi-structured peer discussion process: parents' burdens, individually tailored information, future prospects, isolation, guilt, mortality, and online social interaction. Understanding these themes may assist healthcare professionals provide age-appropriate information and support services that help young people deal with the impact of cancer on daily life. ${ }^{24}$ Moreover, people who know that they are being filmed are susceptible to act and talk in a socially desirable way. This phenomenon may have influenced patients and nurses. In several studies, optimism has been proposed as playing an important role on the multiple pathways to resilience..$^{28}$ As expected, the EG intervention facilitated better perceived competence in participants with pessimistic life orientations over time. However, the same result was obtained for the optimists. Therefore, we cannot conclude that EG intervention was more helpful for pessimistic adolescents compared with optimistic adolescents.

Whether the effect is sufficiently large to justify the use of resources required for the EG intervention is yet to be determined. The improvement in perceived competence might represent a statistical regression to the mean,

\section{REFERENCES}

1. Palmer SL, Reddick WE, Gajjar A. Understanding the cognitive impact on children who are treated for medulloblastoma. J Pediatr Psychol. 2007; 32(9): 1040-9.

2. Gajjar A, Chintagumpala M, Ashley D, Kellie S, Kun LE, Merchant TE, et al. Risk-adapted craniospinal radiotherapy followed by high-dose chemotherapy and stem-cell rescue in children with newly diagnosed medulloblastoma (St Jude Medulloblastoma-96): long-term results from a prospective, multicentre trial. Lancet Oncol. 2006; 7(10): 813-20.

3. Eapen V, Mabrouk A, Bin-Othman S. Attitudes, perceptions, and family coping in pediatric cancer and childhood diabetes. Ann N Y Acad Sci. 2008; 1138(1): 47-9.

4. Classen CC, Kraemer HC, Blasey C, Giese-Davis J, Koopman C, Palesh $\mathrm{OG}$, et al. Supportive-expressive group therapy for primary breast cancer patients: a randomized prospective multicenter trial. Psychooncology 2008; 17(5): 438-47.

5. Helgeson VS, Cohen S. Social support and adjustment to cancer: reconciling descriptive, correlational, and intervention research. Health Psychol. 1996; 15(2): 135-48.

6. Woodgate RL. A different way of being: adolescents' experiences with cancer. Cancer Nurs. 2005; 28(1): 8-15. with some participants benefiting substantially and others much less. Regardless of the type of intervention, all patients displayed progress in all the subscales over time.

\section{CONCLUSION}

Our study has some limitations that should be addressed in future research. Firstly, the majority of the patients participating were able to read and speak. Therefore the results cannot be generalized to children too young to read. Pediatric medulloblastoma is typically diagnosed early, with peak incidence at 5 years of age. Secondly, this study drew its data from a small sample and the data analysis was conducted by a single researcher. Thirdly, it is possible that the benefits of the educational group were due to the group context rather than to the information provided. Future research needs to distinguish the effects of information-giving from the effect of group interaction. Finally, risk-stratification may also be a confounder which influences the outcomes. At the onset of the study, there were no significant differences in medical variables (including risk-stratification) between participants in the two groups, as shown in Table 1. However, as the intervention goes on, high-risk patients might expose to more intensive therapies and harmful over-treatment.

\section{ACKNOWLEDGMENTS}

The authors were truly grateful to researchers from Department of Psychologist, Jiangsu University Affiliated First People's Hospital for their assistance with environmental sampling, and valuable technical support in this study.

7. Geue K, Buttstädt M, Richter R, Böhler U, Singer S. An art education programme for groups in the psycho-oncological after-care. Psychother Psychosom Med Psychol. 2011; 61(3-4): 177-81.

8. Thorsteinsson T, Helms AS, Adamsen L, Andersen LB, Andersen KV, Christensen KB, Hasle et al. Study protocol: Rehabilitation including Social and Physical activity and Education in Children and Teenagers with Cancer (RESPECT). BMC Cancer 2013; 13(1): 544.

9. Lin VW. Tough-skinned kids: identifying psychosocial effects of psoriasis and helping pediatric patients and families cope. J Pediatr Nurs. 2012; 27(6): 56372.

10. Helgeson VS, Cohen S, Schulz R, Yasko J. Education and peer discussion group interventions and adjustment to breast cancer. Arch Gen Psychiatry. 1999; 56(4): 340-7.

11. Helgeson VS, Cohen S, Schulz R, Yasko J. Long-term effects of educational and peer discussion group interventions on adjustment to breast cancer. Health Psychol. 2001; 20(5): 387-92.

12. Rasmussen HN1, Scheier MF, Greenhouse JB. Greenhouse. Optimism and physical health: a meta-analytic review. Ann Behav Med. 2009; 37(3): 239-56.

13. Gustavsson-Lilius M, Julkunen J, Keskivaara P, Lipsanen J, Hietanen P. Predictors of distress in cancer patients and their partners: the role of 
optimism in the sense of coherence construct. Psychol Health 2012; 27(2): 178-95.

14. Friedman LC, Kalidas M, Elledge R, Chang J, Romero C, Husain I, et al. Optimism, social support and psychosocial functioning among women with breast cancer. Psychooncology 2006; 15(7): 595-603.

15. Wang Q, Hay M, Clarke D, Menahem S. Associations between knowledge of disease, depression and anxiety, social support, sense of coherence and optimism with health-related quality of life in an ambulatory sample of adolescents with heart disease. Cardiol Young 2014; 24(01): 126-33.

16. Uitterhoeve R, Bensing J, Dilven E, Donders R, deMulder P, van Achterberg T. Nurse-patient communication in cancer care: does responding to patient's cues predict patient satisfaction with communication. Psychooncology 2009; 18(10): 1060-8.

17. Schou I, Ekeberg O, Karesen R, Sorensen E. Psychosocial intervention as a component of routine breast cancer care-who participates and does it help? Psychooncology 2008; 17(7): 716-20.

18. Walker LS, Claar RL, Garber J. Garber. Social consequences of children's pain: when do they encourage symptom maintenance? J Pediatr Psychol. 2002; 27(8): 689-98.

19. Eapen V, Naqvi A, Al-Dhaheri AS. Cross-cultural validation of Harter's selfperception profile for children in the United Arab Emirates. Ann Saudi Med. 2000; 20(1): 8-11.

20. Lau PW, Lee A, Ransdell L. Parenting style and cultural influences on over weight children's attraction to physical activity. Obesity (Silver Spring) 2007; 15(9): 2293-302.
21. Moyer CA, Ekpo G, Calhoun CL, Greene J, Naik S, Sippola E, et al. Quality of life, optimism/pessimism, and knowledge and attitudes toward HIV Screening among pregnant women in Ghana. Womens Health Issues. 2008; 18(4): 301-9.

22. Scheier MF, Carver CS. Optimism, coping, and health: assessment and implications of generalized outcome expectancies. Health Psychol. 1985; 4(3): 219-47.

23. McCaffrey $\mathrm{CN}$. Major stressors and their effects on the well-being of children with cancer. J Pediatr Nurs. 2006; 21(1): 59-66

24. Wicks L, Mitchell A. The adolescent cancer experience: loss of control and benefit finding. Eur J Cancer Care (Engl). 2010; 19(6): 778-85.

25. Kang JI, Chung HC, Kim SJ, Choi HJ, Ahn JB, Jeung HC, Namkoong K. Standardization of the Korean version of Mini-Mental Adjustment to Cancer K-Mini-MAC) scale: factor structure, reliability and validity. Psychooncology 2008; 17(6): 592-7.

26. Gottardo NG, Gajjar A. Current therapy for medulloblastoma. Curr Treat Options Neurol 2006; 8(4): 319-34.

27. Magrath I, Epelman S. Cancer in adolescents and young adults in countries with limited resources. Curr Oncol Rep. 2013; 15(4): 332-46.

28. Phipps S. Commentary: contexts and challenges in pediatric psychosocial oncology research: chasing moving targets and embracing "good news" outcomes. J Pediatr Psychol. 2005; 30(1): 41-5 